\title{
Chache lavi Deyò: uma reflexão sobre a categoria refúgio a partir da diáspora haitiana no Brasil
}

\author{
- Ana ELISA BERSANi \\ Universidade Estadual de Campinas, Campinas, São Paulo, Brasil
}

DOI 10.11606/issn.2316-9133.v25i25p383-399

\begin{abstract}
resumo $\mathrm{O}$ presente ensaio reflete sobre os sentidos analíticos e políticos do termo refúgio a partir de uma perspectiva que toma tal categoria como constructo social dotado de múltiplos significados. Busca-se revelar e problematizar as dinâmicas sociais e lógicas de classificação articuladas no cenário brasileiro diante da recente chegada dos imigrantes haitianos. Nesse sentido, em um primeiro momento, exploram-se as políticas migratórias adotadas pelo Estado brasileiro para o caso específico dos haitianos e as implicações da criação do "visto permanente por razões humanitárias", observando como as categorias "refugiados" e "imigrantes" foram mobilizadas pelo governo para enquadrar juridicamente ou não os haitianos nas políticas migratórias nacionais. A partir de uma angulação diferente, abordaremos ainda os sentidos sociais da diaspora e a centralidade dessa categoria êmica para a compreensão das lógicas classificatórias em jogo, através da reflexão sobre os valores morais expressos pela obrigação amplamente difundida no Haiti de "Chache lavi Deyō" (buscar melhores meios de vida fora).
\end{abstract}

palavras-chave Diaspora; Migração transnacional; Mobilidade haitiana; Visto humanitário; Refúgio.

\section{Chache lavi Deyò: the refuge category and the case of Haitian diaspo- ra in Brazil}

abstract This essay reflects on the analytical and political meanings of the term refuge from a perspective that takes such a category as a social construct endowed with multiple meanings. It seeks to reveal and problematize the social and logical dynamics of classification articulated in the Brazilian scenario and related to the most recent arrival of Haitian immigrants in the country. Thus, the Brazilian State migratory policies for the specific case of Haitians and the implications of the "permanent visa for humanitarian reasons" creation are explored here. It aims to observe how "refugee" and "immigrant" categories were mobilized by the government to frame Haitians or not in our national migra- 
tion policies. From a different angle, we will reflect on the moral values expressed by the Haitian obligation of "Chache lavi Deyò" (seek better means of living outside), addressing the social senses of diaspora and the centrality of this emic category to the understanding of a classificatory logics at stake.

Keywords Diaspora; Transnational migration; Haitian mobility; Humanitarian Visa; Refuge.

\section{Introdução}

Em julho de 2014 conheci o Fabrice. ${ }^{1}$ Ele havia acabado de chegar ao Brasil e era um dos meus alunos mais interessados e atentos. Fazia perguntas interessantes e, ao contrário dos outros, anotava tudo em um caderno, como se aquelas frases improvisadas pudessem salvá-lo de situações embaraçosas do dia a dia. Naquele momento, eu frequentava uma vez por semana a casa em que ele morava com mais oito haitianos em Campinas para ajudá-los no aprendizado da língua portuguesa. A casa não era pequena e tinha três quartos. Todos eram divididos entre os moradores e os colchões espalhados no chão da forma mais conveniente possível. Além dos habitantes da casa, outros amigos haitianos que moravam no entorno vinham nas noites de quarta-feira para a aula de português. No total, eram, mais ou menos, dez alunos, mas esse número variava a cada semana com a chegada de alguns e a partida de outros. Eu me impressionava com o fato de ter, a cada semana, novos alunos chegando, o que me obrigava a ter sempre material extra.

Eu chegava às 19 horas e nunca conseguia sair antes das 21 horas. Era recebida por alunos sorridentes com a minha presença constante. Eles me contavam como estavam se virando para conseguir emprego e também fatos sobre suas famílias, que tinham ficado no Haiti. Conversávamos muito. Falávamos em crioulo haitiano, o que criava uma relação de confiança quase que imediata. ${ }^{2}$ Também gostávamos de conversar sobre o tempo em que morei no Haiti - quatro meses, entre janeiro e abril de 2013 - fazendo o trabalho de campo para a pesquisa de mestrado. Foi justamente com a intensão de não perder a fluência no crioulo, além de retribuir um pouco aos haitianos a acolhida que recebi em seu país, que comecei a dar aulas de português, como voluntária, aos imigrantes que chegavam ao Brasil. As aulas foram, muitas vezes, improvisadas na sala da casa dos alunos à luz de lanternas, quando não tínhamos eletricidade por conta

\footnotetext{
${ }^{1}$ Os nomes que aparecem nesse trabalho foram alterados com a intenção de preservar as identidades dos interlocutores.

${ }^{2} \mathrm{O}$ crioulo haitiano é a única língua falada por todos no Haiti, que tem também o francês como língua oficial. No entanto, é raro encontrar estrangeiros falantes da língua e por isso eles se surpreendiam tanto com o meu conhecimento da língua.
} 
de problemas na fiação elétrica.

Fabrice estava lá, sentado no sofá e com um sorriso tímido, quando cheguei. Ele é sobrinho de Joseph, um dos moradores da casa, e tinha chegado naquela mesma semana. Não tinha a mesma facilidade de alguns, que já falavam espanhol fluentemente por terem morado na República Dominicana antes de vir para o Brasil. Com o passar do tempo, ficamos amigos. Conversávamos longamente ao final das aulas e, assim, pude acompanhar a sua saga para conseguir um trabalho e a obstinação inspiradora para se expressar sem demora em português. Convivemos semanalmente por alguns meses, até que ele deixou de ir às aulas, pois havia conseguido um trabalho noturno e passou a fazer dupla jornada. Durante o dia, em uma empresa de reciclagem, trabalhava arduamente separando e prensando papelões e, depois, seguia para trabalhar como garçom em uma lanchonete até tarde da noite. Só assim ele poderia dar conta dos gastos pessoais e ainda enviar alguma quantia à família no Haiti. Sua maior preocupação era com a formação dos dois irmãos mais novos que dependiam de sua ajuda.

Fabrice tinha apenas 23 anos. Essa era a sua primeira experiência fora de seu país. Quando completou o ensino médio, em Porto Príncipe, começou a planejar sua viagem para trabalhar no estrangeiro. Como é bastante comum, ele sonhava com o momento da partida e ambicionava chegar aos Estados Unidos, onde, segundo ele, a moeda é mais forte e as possibilidades de trabalho, melhores. Sua família, no entanto, não tinha dinheiro suficiente para patrocinar essa empreitada. O pai, que trabalhava como segurança privado em uma empresa na capital, economizou por anos, planejando cuidadosamente o investimento no filho primogênito que poderia, mais tarde, encarregar-se da educação dos mais jovens. Dois meses antes, seu tio materno havia chegado ao Brasil e se instalado na cidade de Campinas. Fabrice viu essa situação como uma oportunidade única, já que o visto para o Brasil custava menos e ele poderia contar com a ajuda do tio quando chegasse.

Depois de tomada a decisão, Fabrice foi à embaixada brasileira em Porto Príncipe. Para candidatar-se ao visto, válido por cinco anos, é necessário pagar duzentos dólares, ser residente no Haiti, apresentar o passaporte em dia e um atestado de bons antecedentes. Tudo estava certo, mas a demanda pelo visto era tão grande que ele não conseguiu nem mesmo entrar na embaixada para fazer a solicitação. Ele me contou que seria impossível conseguir uma entrevista sem pagar propina a algum intermediário. Ao se dar conta de que não conseguiria o visto, Fabrice ficou desanimado, mas logo soube da possibilidade de entrar no Brasil por terra, de forma indocumentada, pela fronteira norte do país. Uma amiga lhe havia dito que, se tivesse dinheiro para pagar pela travessia, não teria 
problemas para vir. Então ele foi conversar com um raketè, ${ }^{3}$ que lhe cobrou 4 mil dólares para organizar a viagem.

No domingo seguinte, ele foi de ônibus até Santo Domingo, na República Dominicana, onde pegou um avião para a Colômbia. Na Colômbia embarcou em outro voo, dessa vez para o Equador. Chegando em Quito, no Equador, pegou um ônibus para o Perú, daí seguiu de ônibus em ônibus até a fronteira com o Brasil. A viagem de ônibus demorou cerca de quatro dias e foi interrompida algumas vezes por policiais peruanos, que pediram dinheiro para deixá-lo seguir. Quando Fabrice chegou ao Acre, ligou para o tio, que não sabia de sua vinda. Ele se espantou ao saber da distância que teria de percorrer até chegar a Campinas (cerca de oitenta horas de viagem) e assim que o protocolo de solicitação de refúgio foi entregue, dois dias depois, seguiu viagem até o Sudeste. Foi aí que nos conhecemos, na mesma semana de sua chegada.

Naquele momento, em média 20 haitianos por dia entravam no Brasil pela fronteira do Peru com o Acre. Antes de seguir para Rio Branco, onde havia um abrigo improvisado, a maior parte dos recém-chegados pernoitavam em Brasileia, cidade na fronteira que teve o abrigo fechado por falta de estrutura. Durante todo o ano de 2013 foram muitas as polêmicas que envolveram a condição precária em que se encontravam os haitianos nos abrigos improvisados nas cidades fronteiriças. Em abril de 2013, o governador do Acre, Tião Viana, decretou situação de emergência social no município de Brasileia, onde o abrigo, com capacidade para 200 pessoas, abrigava cerca de 1.300 haitianos que permaneciam na cidade à espera dos documentos necessários para seguir viagem. $\mathrm{O}$ governador cobrava da União a responsabilidade pelo provimento dos recursos necessários para a alimentação e habitação dos imigrantes que chegavam. A situação se agravou ainda mais com a cheia do rio Madeira e, no início de 2014, o abrigo precisou ser fechado e transferido para Rio Branco (CONTINGUIBA, 2016, p. 186).

Após esse episódio, o governo do Acre começou a oferecer transporte gratuito para os haitianos que quisessem se dirigir à cidade de São Paulo. Essa medida polêmica colocou a chegada dos haitianos mais uma vez no centro das atenções públicas e foi causa de desavenças políticas entre os governos dos dois estados, que alegavam não dispor dos meios adequados para receber os imigrantes. Entre março e dezembro de 2014, ao menos setenta ônibus partiram de Rio Branco rumo a São Paulo. Mais de 3 mil haitianos foram transportados. Entre eles estava Fabrice.

\footnotetext{
${ }^{3}$ Termo pejorativo usado no Haiti para se referir a pessoas que cobram para realizar diversos tipos de serviços informais ou mesmo ilegais, como, por exemplo, o agenciamento de viagens clandestinas, explorando os seus clientes de alguma forma.
} 
Histórias como a de Fabrice, relacionadas à presença recente dos haitianos no Brasil, que teve início em 2010 e se intensificou de forma marcante entre 2013 e 2014, motivaram as reflexões deste trabalho. Para realizá-las, tomaremos, como fonte privilegiada de estudo, as dinâmicas sociais e as lógicas de classificação articuladas no cenário brasileiro diante da chegada desses imigrantes, com a intenção de compreender como a categoria refúgio é construída e constantemente ressignificada em meio a tantos sentidos políticos e sociais assumidos por ela contemporaneamente.

O que interessa aqui é mostrar como essa categoria, longe de ser autoevidente, é constituída a partir de complexas relações, de forma situacional e contrastiva. Assim, parece-nos bastante frutífera uma análise cruzada, na qual a compreensão do termo refúgio se dá também pela investigação de sua relação com outras categorias presentes no mundo social e implicadas no mesmo contexto, como, por exemplo, imigração e diáspora. ${ }^{4}$ Esses termos não designam apenas o status formal associado aos modos de mobilidade, mas também trazem, incorporados em si, um conjunto de imagens, valores, emoções e práticas que se relacionam às múltiplas experiências vividas pelos atores em questão, tanto nos ambientes públicos como privados.

Nesse sentido, e tendo como pano de fundo a situação dramática dos migrantes e refugiados no contexto global atual, consideramos o "caso haitiano" especialmente prolífico enquanto objeto de reflexão, pois é, a uma só vez, excepcional e paradigmático. Ele dá visibilidade à questão migratória brasileira, revelando os percalços nacionais na acolhida de um fluxo crescente de demandantes de asilo, ao mesmo tempo que, de um ponto de vista mais macro, acentua tensões que rondam os deslocamentos contemporâneos como um todo.

As reflexões levadas a cabo aqui se baseiam em dois momentos de trabalho de campo. O primeiro, realizado entre janeiro e maio de 2013, no departamento de Grand'Anse, no Haiti, durante o desenvolvimento da pesquisa de mestrado que deu origem à dissertação $O$ (extra)ordinário da ajuda: histórias não contadas sobre desastre e generosidade na Grand'Anse, Haiti (2015). O segundo é parte dos esforços de pesquisa empreendidos já na etapa do doutorado e se deu durante o acompanhamento da chegada e da acomodação dos imigrantes haitianos nas cidades de São Paulo e Campinas, entre 2014 e 2016.

\section{Nem imigrante, nem refugiado}

\footnotetext{
${ }^{4}$ Quando grafado sem o acento agudo e em itálico (diaspora) estamos nos referindo à categoria êmica, em crioulo haitiano. Categoria com significado que vai além da ideia de dispersão de um povo, como é comumente usada na língua portuguesa.
} 
A Convenção de 1951 sobre o Estatuto do Refugiado, principal instrumento legal internacional instituído após a criação do Alto Comissariado das Nações Unidas para Refugiados (ACNUR), em 1950, define o refugiado como qualquer pessoa que se encontre fora de seu país de origem e que não possa (ou não deseje) regressar por "fundados temores de perseguição devido à sua raça, religião, nacionalidade, associação a determinado grupo social ou opinião política”. O enquadramento dado ao termo refugiado, aqui, está associado à condição dos europeus deslocados durante a Segunda Guerra Mundial e vem no bojo das diversas negociações diplomáticas que foram realizadas ao longo das décadas de $1950 \mathrm{e}$ 1960. Nesse período, surgiram agências e altos comissariados e estabeleceram-se protocolos e acordos que, apesar de datados e não conclusivos, ainda vigoram e pautam as leis nacionais. Na conjuntura atual, o principal desafio a essa definição tem se colocado em razão do aumento do que se convencionou chamar de "refugiados climáticos". Segundo a Organização das Nações Unidas (ONU), até 2050 haverá cerca de 250 milhões de pessoas nessa situação. De qualquer forma, os deslocamentos causados por razões ambientais ainda não são reconhecidos no âmbito da convenção e, portanto, as pessoas que migram por essas razões não podem ser amparadas pelos órgãos oficiais enquanto tais.

Em termos formais, duas questões fundamentais definem a condição de um refugiado: a primeira está relacionada à necessidade do deslocamento, e o que importa aqui é determinar se ele é voluntário ou imposto por forças externas ao indivíduo; a segunda diz respeito à motivação de tal deslocamento, se econômica ou política. Essas balizas deveriam distinguir os fluxos migratórios, classificando os diferentes tipos de deslocamentos a partir de uma gramática compartilhada internacionalmente. Na prática, como já era de se esperar, a lógica formulada na linguagem do direito não dá conta da complexidade do mundo social. Os movimentos das populações são, portanto, moldados de acordo com interpretações bastante parciais que variam segundo as circunstâncias e os atores sociais implicados no processo de classificação dos mesmos.

De acordo com a linguagem dominante, refugiado é aquele compelido por forças externas, superiores a sua vontade, enquanto o imigrante, reduzido à condição de trabalhador, seria movido por interesses puramente econômicos e de forma voluntária. Juridicamente, a aplicação dessa distinção faz sentido, já que o direito internacional dos refugiados é bastante consolidado na legislação dos Estados, enquanto o direito de migrar ainda não é garantido. No entanto, como afirma Ventura (2016), o aprofundamento das desigualdades econômicas entre os países tem feito com que a diferença clássica entre refúgio e migração se torne cada vez mais tênue. Como classificar emigrados que se deslocaram em razão de ondas de violência urbana, desemprego, fome ou pobreza extrema enquanto "imigrantes econômicos", sem atentar para o fato de que esse movimento não é da ordem da livre escolha? 
No dia 9 de setembro de 2016, em seu primeiro discurso durante uma sessão plenária da Reunião de Alto Nível sobre Grandes Movimentos de Refugiados e Migrantes, na sede da ONU, em Nova York, Michel Temer disse que o Brasil teria recebido, nos últimos anos, 95 mil refugiados provenientes de 79 países diferentes. Os dados aos quais o presidente se referiu no seu "ato falho" incluíam os $85 \mathrm{mil}$ haitianos chegados recentemente no país. A declaração gerou polêmica, já que, de acordo com o Conare (Comitê Nacional para os Refugiados), pouco mais de 8.800 refugiados foram reconhecidos no Brasil, sendo os principais grupos oriundos da Síria, Angola, Colômbia, República Democrática do Congo e Palestina.

Como explicaremos mais adiante, os haitianos não tiveram o pedido de refúgio concedido pelas autoridades nacionais e não se encontram, portanto, protegidos pelas mesmas normas jurídicas que tratam dos outros refugiados, aqueles devidamente reconhecidos como tais. Ao contabilizá-los, intencionalmente, Michel Temer foi acusado de ter "agido de má-fé", embaralhando as categorias imigrantes e refugiados. $\mathrm{O}$ que parece irônico, ou até mesmo dissimulado, nesse caso, é que, ao fazer isso, o presidente burlou a convenção adotada pelo próprio Estado brasileiro, moldando os dados de acordo com a sua intenção de posicionar o país de forma favorável em um cenário internacional no qual essas questões têm mobilizado os debates mais acalorados. Independente das suas "verdadeiras” intenções, a confusão feita entre essas categorias é bastante comum. O que nos interessa aqui é, antes, o escrutínio das dinâmicas sociais que se revelam pelo uso de determinadas categorias quando colocadas em relação às circunstâncias de sua enunciação.

Assim, em vez de buscarmos a melhor definição para a situação dos haitianos no Brasil, devemos nos indagar sobre as condições que tornaram a afirmação de Temer possível, para além da aparente contradição entre discurso e prática que ela revela. Mais do que uma estratégia retórica vazia de sentido, dizer que os haitianos foram recebidos enquanto refugiados é algo mesmo possível diante da profunda indeterminação que marca a condição dessas pessoas no contexto nacional. A análise do "caso haitiano" no Brasil se faz ainda mais interessante, pois mostra como essa mesma indeterminação entre refúgio e imigração impôs obstáculos, dificultando a legislação, mas também abriu novas possibilidades, pressionando as políticas migratórias.

Apesar de a mobilidade ser um fenômeno antigo e estrutural entre os haitianos, o recente fluxo desses sujeitos para o Brasil se iniciou de forma bastante tímida em 2010. Nos meses que se seguiram ao terremoto que atingiu a ilha, em janeiro daquele ano, pequenos grupos começaram a chegar à Tabatinga, município localizado ao norte do estado do Amazonas, na tríplice fronteira do Brasil com o Peru e a Colômbia. Sabe-se que esses primeiros grupos tinham a intenção de alcançar a Guiana Francesa, e o Brasil seria apenas um território de passagem, uma espécie de "corredor" (HANDERSON, 2015). Porém, aos poucos, muitos 
foram permanecendo no país. No final de 2011 e início de 2012, a imigração se intensificou notoriamente e atingiu o seu ápice entre 2013 e 2014. Os haitianos adentraram o país principalmente pelas fronteiras do Acre e do Amazonas, mas, aos poucos, utilizando-se de diferentes rotas, foram chegando aos estados do sul, em busca de trabalho.

A novidade desse fluxo - da perspectiva brasileira - despertou grande interesse da mídia, que passou a veicular notícias de caráter alarmante, passando a ideia de que estava em curso uma iminente "invasão" de haitianos no país ainda que os números reais dessa migração não devessem preocupar, sobretudo se colocados em perspectiva com a grandeza do nosso território e da nossa população. Marcado por um profundo desconhecimento das dinâmicas e dos processos migratórios, e das reais razões dos deslocamentos, o estardalhaço criado pela mídia ressoou a forma como a imprensa internacional tratou a "crise dos refugiados" na Europa nos últimos dois anos. De forma semelhante, a linguagem da crise e da emergência foi mobilizada sempre que se noticiou o novo fluxo de haitianos para o Brasil, fato que também justificava a abordagem da situação de forma ambígua, ora pelo viés humanitário, ora pela securitização. Enquanto se fala de uma massa genérica de pessoas oriundas de países pobres e conflituosos dirigindo-se a países mais desenvolvidos, e, assim, pressionando os sistemas de proteção social e o mercado de trabalho nessas localidades, a experiência concreta de mobilidade vivenciada pelos migrantes e refugiados vai sendo continuamente obliterada.

Apesar de serem, quase sempre, retratados como uma massa de pessoas desesperadas fugindo do caos provocado pelo terremoto de 2010 no Haiti, os imigrantes que chegam ao Brasil têm trajetórias bastante diversas e as razões que os fizeram deixar o país de origem não se resumem às consequências do desastre. Enquanto estive no Haiti, convivi com jovens que, como Fabrice - que vivia num universo de forte tradição de mobilidade em escala local, regional e (trans) nacional -, desde a adolescência sonham em deixar o país. A mobilidade, ou, para usar uma expressão muito comum no Haiti, chache lavi deyò (buscar a vida ou os meios para se viver fora), é a perspectiva de futuro de boa parte da população e, na maior parte dos casos, a própria motivação de deixar o país é a possibilidade de assegurar melhores condições de vida para os familiares que ficam.

As práticas migratórias dessa população estão ancoradas no contexto mais amplo de expansão do capitalismo que, aos poucos, incorporou os haitianos como mão de obra importada e marginalizada. ${ }^{5}$ Aproximadamente, entre 4 a 5 milhões de haitianos estão espalhados pelo mundo, sobretudo na França, Estados Unidos, Canadá e outros países do Caribe, segundo os dados oficiais do Ministério dos Haitianos Residentes no Exterior (MHAVE). A rota Haiti-Brasil,

${ }^{5}$ Para uma discussão aprofundada sobre migração haitiana ver Richman, 2005. 
que surge de forma mais evidente nos últimos seis anos, está associada, sobretudo, à construção da ideia de "terra de oportunidades" difundida aos poucos, em razão do papel político e econômico de destaque que o Brasil passa a ocupar no cenário mundial. A postura pública de abertura e hospitalidade adotada internacionalmente pelo governo brasileiro e a expectativa da existência de uma demanda de mão de obra para o trabalho nas obras da Copa do Mundo de 2014, entre outros fatores, contribuíram para que o Brasil deixasse de ser um "corredor de passagem" e se tornasse o novo destino da diáspora haitiana.

\section{O “visto humanitário"}

Em 2010, quando começaram a chegar ao território brasileiro pela via terrestre e de forma indocumentada, os haitianos tiveram acesso ao protocolo de solicitação de refúgio que valia como uma espécie de comprovante de entrada e tornava possível a retirada de documentos como a carteira de trabalho, válida por um ano, e o cadastro de pessoa física na Receita Federal (CPF), enquanto o pedido de refúgio era analisado. Diante da dificuldade e da demora em se conseguir um visto na embaixada brasileira em Porto Príncipe, muitos haitianos com planos de chegar ao nosso país adotaram a rota amazônica e a solicitação de refúgio como estratégia de entrada, já que do ponto de vista legal, enquanto signatário da convenção de Genebra de 1951, o Brasil não pode negar a solicitação a nenhum estrangeiro que chegue sem visto ao território nacional. Com o protocolo em mãos, os imigrantes ficam temporariamente regularizados, ao menos durante o tempo de análise do pedido de refúgio.

Naquele momento havia a expectativa de que esse novo fluxo fosse passageiro, porém, à medida que o tempo passava, a situação nas cidades fronteiriças, principalmente em Tabatinga (Amazonas) e em Brasileia (Acre), se agravava. A chegada dos haitianos evidenciou a falta de uma política migratória eficaz por parte do governo federal e começou a incomodar. Como já afirmamos, a mídia desempenhou um importante papel na construção da falsa ideia de "invasão haitiana", disseminando o sentimento de medo e a imagem do imigrante como ameaça potencial, do ponto de vista não apenas da segurança como também da saúde pública nacionais.

Diante desse cenário e temendo que o número de demandantes de refúgio de origem haitiana aumentasse de forma incontrolável, o Ministério de Relações Exteriores (MRE) informou que os haitianos não se enquadravam na categoria de refugiados. Ainda que tivessem deixado o Haiti devido às consequências do terremoto, tal situação não estaria de acordo com a lei 9.474, de 1997, que reconhece como refugiado apenas o indivíduo que estiver sendo perseguido no país de origem por motivos de raça, religião, conflito político ou violação de direitos humanos. Naquela ocasião, o MRE destacou, ainda, que os tratados interna- 
cionais e a legislação brasileira não preveem o reconhecimento da condição de refugiado às pessoas que se deslocam em busca de melhores condições de vida e de trabalho, recorrendo à clássica distinção entre "imigrantes econômicos" e "refugiados" para justificar as medidas que viriam a ser tomadas.

A lei de refúgio brasileira de 1997 - a mesma citada pelo MRE para justificar a exclusão dos haitianos dessa circunscrição - incorpora uma definição mais abrangente da categoria refugiado, aquela estabelecida pela Declaração de Cartagena (1984). Nela, refugiado é "todo aquele que tenha saído de seu país devido à grave e generalizada violação de direitos humanos". Ainda assim, no caso dos haitianos, não se pôde considerar o terremoto como um agente de perseguição e, portanto, tais imigrantes não puderam ser amparados pela lei de refúgio. Como sabemos, por mais avançada que se considere a legislação nacional sobre esse tema, a sua aplicação está sempre sujeita à interpretação que se faz dela e aos interesses políticos em jogo.

Nesse sentido, havia ainda uma razão diplomática para que o pedido de refúgio não fosse concedido pelas autoridades brasileiras. Conceder o status de refúgio aos solicitantes que chegavam ao Brasil exigiria o reconhecimento da existência de violações de direitos humanos no Haiti. Ora, isso seria o mesmo que assumir o fracasso da Missão das Nações Unidas para a Estabilização do Haiti (Minustah), comandada pelo Brasil desde 2004, cujo objetivo oficial era restabelecer a segurança do país após as sucessivas crises políticas que culminaram no exílio do então presidente Bertrand Aristide e em recorrentes ondas de violência.

Apesar de ter negado o refúgio aos haitianos, o Comitê Nacional para os Refugiados (Conare) reconheceu que eles teriam sofrido uma forma de deslocamento forçado e que, portanto, necessitavam de proteção humanitária. Os protocolos foram então encaminhados para a apreciação do Conselho Nacional de Imigração (CNIg) como um caso especial. Mais tarde, na tentativa de encontrar uma solução para o caso, acabar com a rota amazônica de entrada de imigrantes irregulares no país e criar um novo dispositivo legal para acolher os haitianos, o governo brasileiro promulgou em 12 de janeiro de 2012 a Resolução Normativa no 97/2012, que "dispõe sobre a concessão do visto permanente previsto no art. 16 da lei $\mathrm{n}^{\mathrm{0}}$ 6.815, de 19 de agosto de 1980, a nacionais do Haiti” por razões humanitárias.

A partir da proposta do CNIg, o dispositivo que passou a ser popularmente chamado de "visto humanitário", até então inexistente na legislação brasileira, passou a vigorar justificado pela dramática situação social e política do Haiti, agravada após o terremoto em 2010. Essa medida estabelecia que os haitianos que quisessem vir ao Brasil teriam o visto expedido na embaixada de Porto Príncipe e impunha uma restrição à concessão, determinando uma cota máxima de 100 vistos por mês (ou 1.200 vistos por ano). Se, por um lado, a resolução normativa criava novas possibilidades de entrada regular no país aos haitianos, por 
outro, representou uma política de controle do fluxo migratório haitiano extremamente arbitrária.

Também aqui estamos diante da lógica aparentemente contraditória que marca não apenas a condição dos imigrantes e refugiados no mundo contemporâneo, mas também o tratamento dado a eles. A criação do "visto humanitário" foi um feito exaltado pelos porta-vozes do governo brasileiro, mas apresentava evidentes ambiguidades (MARONI DA SILVA, 2016, p. 343). Ao mesmo tempo que protege e regulariza, tal mecanismo impõe sansões e controla.

Sob as críticas contundentes de acadêmicos e ativistas sociais que alegaram ser essa uma medida discriminatória e que representava um retrocesso na política migratória nacional, ${ }^{6}$ o governo brasileiro alterou o artigo segundo da Resolução Normativa 97 através de outra Resolução, a de número 102, de 26 de abril de 2013, que ampliou a possibilidade de concessão do visto humanitário em outros consulados, como é o caso do Equador, e derrubou o limite de concessão dos vistos.

No entanto, a entrada de haitianos desprovidos do visto humanitário pelas fronteiras do país continuou a ser rotina e a solicitação de refúgio a principal via de regularização dos mesmos pelo menos até 2014 (SILVA, 2016, p. 222). Assim como aconteceu com Fabrice, muitos outros precisaram optar pela rota terrestre em decorrência da falta de uma política eficaz para a concessão de vistos no Haiti que estivesse alinhada à resolução do CNIg. Também foram muito comuns, nesse período, os relatos sobre atuação ilegal de intermediários dispostos a agilizar o andamento dos tramites burocráticos nas embaixadas aos que pudessem pagar mais pela emissão do visto.

De forma bastante geral, após entrar no território brasileiro e solicitar o refúgio na Polícia Federal, os haitianos seguem viagem rumo a outros estados. De posse do protocolo de solicitação de refúgio, eles podem solicitar a emissão do CPF e da carteira de trabalho, os quais, no entanto, podem não ser reconhecidos por instituições como bancos, universidades ou imobiliárias. Como parte do processo institucionalizado nesse período, os pedidos de refúgio vindos de haitianos são logo encaminhados ao CNIg, e não ao Conare, para dar entrada aos procedimentos do visto humanitário. Enquanto aguardam a permissão de residência no Brasil - trâmite bastante demorado e que pode levar até três anos para ser concluído com a concessão do Registro Nacional de Estrangeiro (RNE) - essas pessoas, que já se encontram bastante vulneráveis depois de terem passado pelos perigos e violações enfrentados no trajeto até aqui, são muitas vezes obrigadas à clandestinidade.

Diante do fracasso da medida e das dificuldades de integração dos imigrantes, no dia 11 de novembro de 2015, o governo brasileiro toma mais uma deci-

${ }^{6}$ Para um exemplo dessa crítica ver Thomaz, 2012. 
são e concede residência permanente a 43.781 haitianos que haviam solicitado refúgio ao Conare entre 2011 e 2015. Os casos foram encaminhados ao CNIg que, através da normativa número 27 , concedeu a autorização de residência. $\mathrm{Na}$ prática, porém, essas concessões não puderam ser todas efetivadas no prazo previsto, devido, entre outras coisas, à lentidão do trâmite burocrático - que exige o encaminhamento de documentos oficiais como a certidão de nascimento e de casamento, todas devidamente traduzidas para o português por um tradutor juramentado - e ao alto custo para a emissão do RNE, que, incluindo todas as taxas, pode chegar a $\mathrm{R} \$ 450,00$.

Em setembro de 2016, o CNIg prorrogou pelo quarto ano consecutivo a vigência da Resolução Normativa 97, que permanecerá em vigor, dessa vez, até outubro de 2017. Assim, a formalização através da concessão do "visto humanitário” ou da efetivação de residência permanente poderá continuar pelo menos por mais doze meses. Segundo os dados oficiais recentemente divulgados pelo CNIg, entre janeiro de 2012 e maio de 2016, foram emitidos 48.361 vistos e 51.124 autorizações de residência a haitianos no Brasil.

Ao longo do tortuoso processo burocrático descrito aqui, as categorias, que não são neutras, foram sendo mobilizadas para enquadrar juridicamente (ou não) os recém-chegados nas políticas migratórias nacionais. Ao negar o status de refugiado, o governo brasileiro rejeitou a possibilidade de qualquer haitiano se enquadrar na definição mais clássica de refúgio, ou seja, excluiu esses sujeitos de um sistema de proteção mais robusto. Porém, a ambiguidade do caso, o qual, segundo o próprio Conare, deveria ser tratado a partir do marco jurídico da migração forçada, demandando uma proteção diferenciada, colocou um impasse que desafiou o Estado brasileiro ao reconhecimento de uma nova possibilidade migratória e à criação de novas políticas.

A opção feita com a criação do "visto humanitário" representou uma espécie de terceira via que manteve a ambiguidade no tratamento desse fluxo migratório. De toda forma, essa é uma medida excepcional, bastante específica e temporária, já que é um mecanismo de proteção humanitária mobilizado em resposta à situação extraordinária causada pelo terremoto. Pouco se sabe sobre a forma como a questão migratória será abordada daqui para frente e se essa será uma política adotada para responder às novas demandas.

\section{Indesejados}

A gramática de classificação dos tipos de mobilidade se dá a partir da articulação com as lógicas de proteção e de controle; lógicas distintas que, apesar de aparentemente contraditórias, coexistem e competem entre si no bojo das políticas do Estado. Esse jogo, portanto, não é estável. A experiência de deslocamento dos sujeitos vai sendo ajustada ao longo do processo burocrático e ganha 
enquadramentos distintos em diferentes momentos. Com a criação do "visto humanitário", inclusive do ponto de vista jurídico, a ambiguidade se torna um lugar possível para os haitianos no contexto das políticas brasileiras.

Uma vez que as categorias do mundo social não são coisa dada, se quisermos compreender de forma mais abrangente os sentidos da ideia de refúgio, é preciso tomar o conjunto das tramas implicadas nessa relação. Ao deslocar o ângulo de análise, sem desconsiderar suas importantes inflexões, mas deixando as determinações do Estado e seus agentes de lado, constatamos que para a sociedade como um todo o contraste entre tais categorias perde sentido. Quase não se estabelece diferença entre os conceitos e categorias juridicamente definidos. Imigrantes, documentados ou não, solicitantes de refúgio, refugiados estatutários ou indeferidos, portadores de "visto humanitário", todos são considerados estrangeiros e, a princípio, ilegítimos.

Não obstante o fato de os haitianos não serem considerados oficialmente refugiados, talvez em consequência à terrível situação em que sem encontravam nos abrigos nas cidades fronteiriças - situação bastante análoga à dos refugiados mantidos nos campos da Grécia, por exemplo - ou ainda pelo tratamento que lhes é comumente dispensado, a mídia brasileira acabou por difundir a imagem do imigrante haitiano como refugiado. Tal representação, no entanto, ainda que provoque comoção em muitos, não garante aos haitianos nenhuma proteção especial no âmbito das interações cotidianas. Observamos aqui o deslizamento semântico da ideia de refúgio, que já não aparece, como na lógica jurídica, associada a uma efetiva garantia do direito de se deslocar, mas sim a um fluxo anormal, irregular, clandestino e até mesmo ilegal.

A percepção de que essas pessoas, independentemente do tipo de permissão que possuem, representam uma ameaça, fica evidente na forma como são retratadas pela opinião pública. Elas trariam riscos à nação, aumentando o desemprego, disseminando doenças e aumentando a criminalidade, por exemplo.

Ao longo de 2014, mesmo ano da chegada de Fabrice ao Brasil, dezoito haitianos denunciaram ter sofrido espancamentos dentro das empresas em que trabalhavam, na cidade de Curitiba, no Paraná. No dia primeiro de agosto de 2015, um grupo de homens atirou com uma espingarda de chumbinho contra seis haitianos na rua do Glicério, em São Paulo, em frente à paróquia Nossa Senhora da Paz local que é referência na acolhida a imigrantes e refugiados na cidade. Naquele mesmo mês, o muro do cemitério de Nova Odessa, cidade próxima a Campinas, foi pichado com a frase "Back to Haiti" ("Voltem ao Haiti"). Mais recentemente, na madrugada do sábado de 14 de maio de 2016, o universitário haitiano Getho Mondesi, estudante do terceiro semestre do curso de Administração Pública e Políticas Públicas da Unila, foi violentamente atacado por um grupo de jovens no centro de Foz do Iguaçu, no Paraná. Usando expressões de cunho racista e xenófobo, eles o agrediram com garrafas de vidro. Getho estava a caminho da rodoviária, 
onde pegaria um ônibus com destino a Cascavel para passar a semana com seu filho de oito meses.

Episódios de xenofobia e de violência injustificada contra os atuais grupos de imigrantes no Brasil não são casos isolados. A hostilidade a que são expostos ao longo da chegada e acomodação no Brasil deve ser compreendida em relação ao histórico dos fluxos migratórios para o nosso país. Nos últimos anos, a onda migratória formada pelos bolivianos e peruanos foi reforçada pelos senegaleses, congoleses e haitianos, configurando um tipo de imigração que vem ao revés dos antigos pressupostos históricos que elegeram o branco-europeu como modelo do "imigrante desejável" no nosso país.

Ainda que da ordem do não dito, há uma gramática que opera o tempo todo distinguindo os recém-chegados em dois grupos: os desejáveis e os indesejáveis. Quando atentamos aos constrangimentos sociais de várias ordens por que passam, outros fatores, como raça e nacionalidade, se sobressaem, determinando a experiência de vulnerabilidade dessas pessoas. Dessa perspectiva, uma equação complexa entre as lógicas da proteção/humanitarismo e do controle/securitização também determina quais vidas são mais ou menos adequadas.

\section{Sobre a diaspora}

Durante os dois anos em que acompanhei de perto a chegada dos haitianos nas cidades de Campinas e São Paulo, chamava-me atenção a forma como toda a polêmica em torno das múltiplas possibilidades classificatórias e as implicações políticas das mesmas parecia não impactar a percepção que eles tinham da própria condição. Claramente, a chance de regularização por meio da solicitação de refúgio lhes interessava, e suas trajetórias se moldavam de acordo com as possibilidades burocráticas disponíveis. No entanto, a categoria utilizada por eles para falar de si curiosamente contrasta com a ideia mais clássica de refúgio.

O termo diaspora, como afirma Handerson (2015, p. 59), qualifica os haitianos que se encontram no estrangeiro e designa a comunidade haitiana transnacional. Quando falam sobre a própria experiência de mobilidade, é essa a categoria que os define: Mwen se diaspora (Eu sou diáspora). Ao contrário da ideia de fuga que carrega o termo refúgio, a categoria êmica diaspora, amplamente utilizada entre os haitianos, traz como marca a ideia de pertencimento, de manutenção dos laços com o país de origem. Dessa forma, e a partir de outros marcos, se expressam uma infinidade de elementos implicados no movimento migratório, tais como status, projetos, motivos, ideais etc.

No Haiti, tive a oportunidade de presenciar diversas situações que revelaram a importância desse conceito para a compreensão das dinâmicas sociais do país,

${ }^{7}$ A esse respeito, conferir Azevedo, 1987 e Seyferth, 2002. 
o qual serve de ancora a uma comunidade móvel e transnacional de enorme proporção. No Haiti, a grande maioria das famílias têm, pelo menos, um de seus membros vivendo no exterior. Na pesquisa que desenvolvi durante a acomodação da população aflita que saiu da região de Porto Príncipe para o departamento da Grand'Anse após o terremoto de 2010, me debrucei sobre uma economia moral singular e ordinária, centrada na partilha e nas obrigações recíprocas de auxílio que se estendem para além do grupo doméstico e dos limites territoriais.

Grande parte dos recursos financeiros que permitiram as viagens de resgate dos desabrigados e feridos chegaram através de remessas enviadas pelos haitianos que, vivendo fora do país, também se comprometeram com a ajuda. $\mathrm{O}$ auxílio da comunidade haitiana que vive fora do país, denominada diaspora, foi essencial também naquele período em que os sobreviventes foram abrigados na Grand'Anse. ${ }^{8}$ Eles enviavam somas maiores dependendo da necessidade de seus parentes e eram acionados sempre que fosse preciso custear rituais funerários, a compra de medicamentos, internações, viagens a Porto-Príncipe para resolver assuntos pendentes ou, ainda, para possibilitar o empreendimento de novos negócios comerciais.

Os estudos sobre a diáspora revelam que os migrantes, ainda que tenham saído de suas comunidades de origem, não deixam de fazer parte de uma comunidade que também se reproduz apesar e através da distância. Como a história de Fabrice, contada no início deste texto, exemplifica, a própria motivação de deixar o país está na maioria das vezes associada à possibilidade de assegurar melhores condições de vida para os familiares que ficam no Haiti. Como afirma Richman, a inevitabilidade da migração no sentido de dar melhores condições à família é internalizada desde cedo pelos jovens que continuam a fazer parte de tal dinâmica de reciprocidade, ainda que fora do território nacional (2005).

Dessa perspectiva, fica claro que a categoria refúgio não dá conta da experiência social haitiana, que ficaria obscurecida se a tomássemos enquanto evidência e não objeto de análise. A expressão "chache lavi deyō" (buscar a vida fora), muito utilizada no Haiti quando se indaga acerca dos familiares que estão distantes, dá-nos dicas importantes sobre a complexidade dos fluxos migratórios que a crise dos refugiados trouxe à tona mais recentemente no cenário global. Ao operar fora da lógica dicotômica das categorias normativas utilizadas pelo direito internacional, a diaspora haitiana revela a mobilidade humana enquanto fenômeno multifacetado e cheio de nuances, a um só tempo livre e obrigatório.

\footnotetext{
${ }^{8}$ As remessas de capital vindas de fora do país através da diáspora representam uma parte importante dos recursos que mantêm o país durante os longos períodos de crise econômica.
} 


\section{Referências bibliográficas}

ALTO COMISSARIADO DAS NAÇÕES UNIDAS PARA REFUGIADO (ACNUR). Refúgio no Brasil: uma análise estatística (janeiro de 2010 a outubro de 2014), Brasília: Acnur, 2014.

AZEVEDO, Celia Maria Marinho de. Onda negra, medo branco: o negro no imaginário das elites - século XIX. Rio de Janeiro: Paz e Terra, 1987.

BAENINGER, R.; SOARES, W. Perfil migratório do Brasil. Texto preliminar/ OIM. Brasília: 2009 (mimeo).

BAENINGER, R. Rotatividade migratória: um novo olhar para as migrações internas no Brasil. Revista Interdisciplinar da Mobilidade Humana, v. 20, n. 39, p. 77-100, 2012.

BERSANI, Ana Elisa. O (extra)ordinário da ajuda: histórias não contadas sobre desastre e generosidade na Grand'Anse, Haiti. Campinas, 2015. Dissertação (Mestrado) - Programa de Pós-Graduação em Antropologia Social, Universidade Estadual de Campinas (Unicamp).

COTINGUIBA, Marília Lima Pimentel; COTINGUIBA, Geraldo Castro. Fronteiras e aspectos do rito de mudança de categoria jurídico-política dos sujeitos haitianos em mobilidade transnacional no Brasil. In: BAENINGER, R.; PERES, R.; FERNANDES, D.; SILVA, S. et al. (Orgs.). Imigração haitiana no Brasil. Jundiaí (SP): Paco Editorial, 2016.

FERNANDES, D; MILESI, R; FARIAS, A. Do Haiti para o Brasil: o novo fluxo migratório. Cadernos de Debates, Instituto Migrações e Direitos Humanos e ACNUR, Brasília, n. 6, p. 73-97, 2012.

HANDERSON, J. Diaspora, as dinâmicas da mobilidade haitiana no Brasil, no Suriname e na Guiana Francesa. Rio de janeiro, 2015. Tese (Doutorado) - Programa de Pós-Graduação em Antropologia Social, Universidade Federal do Rio de Janeiro (UFRJ).

Diaspora. Sentidos sociais e mobilidades haitianas. Horizontes Antropológicos, Porto Alegre, ano 21, n. 43, p. 51-78, 2015. Disponível em: <http:// dx.doi.org/10.1590/S0104-71832015000100003>. Acesso em : 26 dez. 2016.

MARONI DA SILVA, Paloma Karuza. O visto humanitário como política migratória: o caso da imigração haitiana com destino ao Brasil. In: BAENINGER, R.; PERES, R.; FERNANDES, D.; SILVA, S. et al. (Orgs.). Imigração haitiana no Brasil. Jundiaí (SP): Paco Editorial, 2016.

PATARRA, Neide L. O Brasil: país de imigração? Revista eletrônica e-metropolis, ano 3, n. 9, 2012. Disponível em: <http://emetropolis.net/system/edicoes/ arquivo_pdfs/000/000/008/original/emetropolis_n09.pdf?1447896326>. Acesso em: 30 abr. 2017.

RICHMAN, K. Miami Money and the Home Gal. Anthropology and Humanism, Arlington, v. 27, n. 2, p. 119-132, 2003. 
Migration and Vodou. Gainesville (EUA): University Press of Florida, 2005.

SEYFERTH, Giralda. Colonização, imigração e a questão racial no Brasil. Revista USP, São Paulo, n. 53, p. 117-149, 2002.

SILVA, Sidney Antonio. A imigração haitiana e os paradoxos do visto humanitário. In: BAENINGER, R.; PERES, R.; FERNANDES, D.; SILVA, S. et al. (Orgs.). Imigração haitiana no Brasil. Jundiaí (SP): Paco Editorial, 2016.

THOMAZ, Omar R.; NASCIMENTO, Sebastião. Por que não o Haiti? Carta Capital, 2012. Disponível em: <http://www.cartacapital.com.br/educacao/ por-que-nao-o-haiti>. Acesso em: 23 mai. 2017.

VENTURA, Deisy; ILLES, Paulo. Qual a política migratória do Brasil? Le Monde Diplomatique Brasil, 2012. Disponível em: <http://www.diplomatique.org. br/qual-a-politica-migratoria-do-brasil >. Acesso em: 23 mai. 2017.

VENTURA, Deisy. Entrevista: migrações internacionais e seus fluxos de contradições. Panorama Internacional, ano 1, n. 3, 2016. Disponível em: <http:// panoramainternacional.fee.tche.br/article/migracoes-internacionais-e-seus-fluxos-de-contradicoes/>. Acesso em: 30 abr. 2017.

\section{Ana Elisa Bersani}

Bacharel em Ciências Sociais pela Universidade de São Paulo (2010) e mestra em Antropologia Social pela Universidade Estadual de Campinas. Atualmente é doutoranda no Programa de Pós-Graduação em Antropologia Social da Universidade Estadual de Campinas (PPGAS - Unicamp), onde desenvolve pesquisa com especial interesse nas áreas de Antropologia Médica, Antropologia do Desenvolvimento e da Ajuda Humanitária, com ênfase em contextos de crise e pós-desastre.

Recebido em 07/04/2017 Aceito para publicação em 07/04/2017 